\title{
Amplitude Modulation of Atomic Wavefunctions Final Technical Report
}

\author{
William E. Cooke \\ Department of Physics \\ College of William and Mary \\ Williamsburg, Virginia 23187-8DOE Patent Clearance Granted \\ DE-FG02-97-ER 14800, August 200/yDversule $\frac{4-3.02}{\text { Mark P. Dvorscak }}$ \\ (630) 252-2393 \\ E-mail mark.dvorscak@ch.doe.gov \\ Office of intellectual Property Law \\ DOE Chicago Operations Office
}

\section{Results}

This project developed a novel wave function modulation technique. Other modulation techniques use tailored laser pulses to directly excite a time-dependent, modulated wave function from a ground state. Our technique began with one electron already excited to a time independent eigenfunction. Then, by using excitations of a second valence electron, we modulated the other wave function. Our technique had the benefit that it was very efficient, and required low power lasers with no need for precise phase or amplitude control. On the other hand it had the difficulty of being a mult-step laser excitation with a maximum repetition rate of $10 \mathrm{~Hz}$. Over the course of this project, we showed that the technique did work, and work efficiently. However, it was easy to generalize: Since the modulation depended on a difference between electron-electron interactions with the inner electron in a ground or excited state, the efficiency of the modulation was strongly state dependent. For example, we never showed any significant modulation in our tests of barium states, while our strontium measurements did show efficient modulation as long as the state to be modulated was in the $5 s n d$ group with $n$ between 30 and 50. We completed some studies of the dependence of the amplitude modulation as we varied the time between the excitation and de-excitation pulses applied to the inner electron. The amplitude of the nearest neighbor states was well described by Multi-Channel Quantum Defect theory, but farther satellites were problematical. This may have simply reflected the low density of measurement points, since the amplitudes of the farther satellites oscillate more quickly with time.

As we developed our technique, we showed that we could directly measure autoionization decay rates in the time domain, and that the net effect of a state belonging to a Rydberg series was that exponential decay could not be measured, since any short excitation created a coherent superposition that decayed with significant structure.

In addition, we showed that these short-lived states could not be power-broadened in the normal sense. Instead, even at very high power densities, we observed unbroadened, but saturated line shapes. This was a verification of calculations that showed that a when a cosecant-squared pulse shape drives a two level system, that the time and frequency dependencies factor. This means that the entire line shape amplitude varies with pulse power, but that its width and central position are insensitive to driving power. 


\section{DISCLAIMER}

This report was prepared as an account of work sponsored by an agency of the United States Government. Neither the United States Governmeat nor any ageacy thereof, nor any of their employees, makes any warranty, express or implied, or assumes any legal liability or responsibility for the accuracy, completeress, or usefulness of any information, apparates, produet, or process disclosed, or represents that its use would not infringe privately owned rights. Reference berein to any specific commercial produch, process, or service by trade name, trademark, manufactures, or otherwise does not necessarily constitute or imply its endorsement, recommendation, or favoriag by the United States Government or any ageney thereof. The riews and opinions of authors expressed herein do not necessarily state or reflect those of the United States Government or any agency thereof. 


\section{DISCLAIMER}

Portions of this document may be illegible in electronic image products. Images are produced from the best available original document. 


\section{Graduate Students}

This program has supported three graduate students who have completed their $\mathrm{Ph} . \mathrm{D}$. degrees, and one who is completing her final manuscript for and will then receive the Ph.D. degree. The three who have completed their degrees are:

Lei Zhou (1995)

Grzegorz Waligorski (1997),

Jonathan Curley (2000)

The student who will receive her Ph.D. degree by June 2002 is Julie Grossen.

\section{Recent Publications}

"Measuring angular distributions with large-acceptance-angle detectors", Grzegorz Waligorski and W. E. Cooke, Meas. Sci. Technol. 12, 299, (2001)

"Technique for measuring the linewidth of autoionizing Rydberg states," Grzegorz Waligorski, Lei Zhou, and W. E. Cooke, Physical Review A 55, 1544 (1997). 
Our final effort was to further develop half-cycle pulses (HCP) as a fast Rydberg state analysis tool. Previous studies had used HCP to ionize Rydberg states, but most of the Rydberg population typically redistributes, rather than ionizes. We developed a new Rydberg state detector to analyze final state populations with a much higher sensitivity to $n$ and $l$.

This method combined Selective Field Ionization (SFI), which determines the relative population in each Rydberg state, with Isolated Core Excitation (ICE), which generates a specific excitation profile for different $n$ and $l$ states. This combination allowed us to detect Rydberg state redistribution, even from a $n=35$ Rydberg state. The accompanying figure shows the results of applying a modest $(\sim 1.2 \mathrm{KV} / \mathrm{cm}) \mathrm{HCP}$ to a barium $6 s 35 d$ state. The right-hand panel shows the SFI signature, which had been a single peak at $280 \mathrm{~ns}$ in the absence of the HCP. The left-hand panel shows an ICE spectrum taken at each of the time delays designated by the arrows. The wealth of structure allows us to unambiguously identify the myriad of states that are overlapping in their SFI spectra, and the far-left identifies the major component of that spectrum. For example, the clear, sharp peaks in the spectrum at 330 ns identify that as almost entirely due to the $6 s 35 p$ state, even though it is not distinct in the SFI spectra.

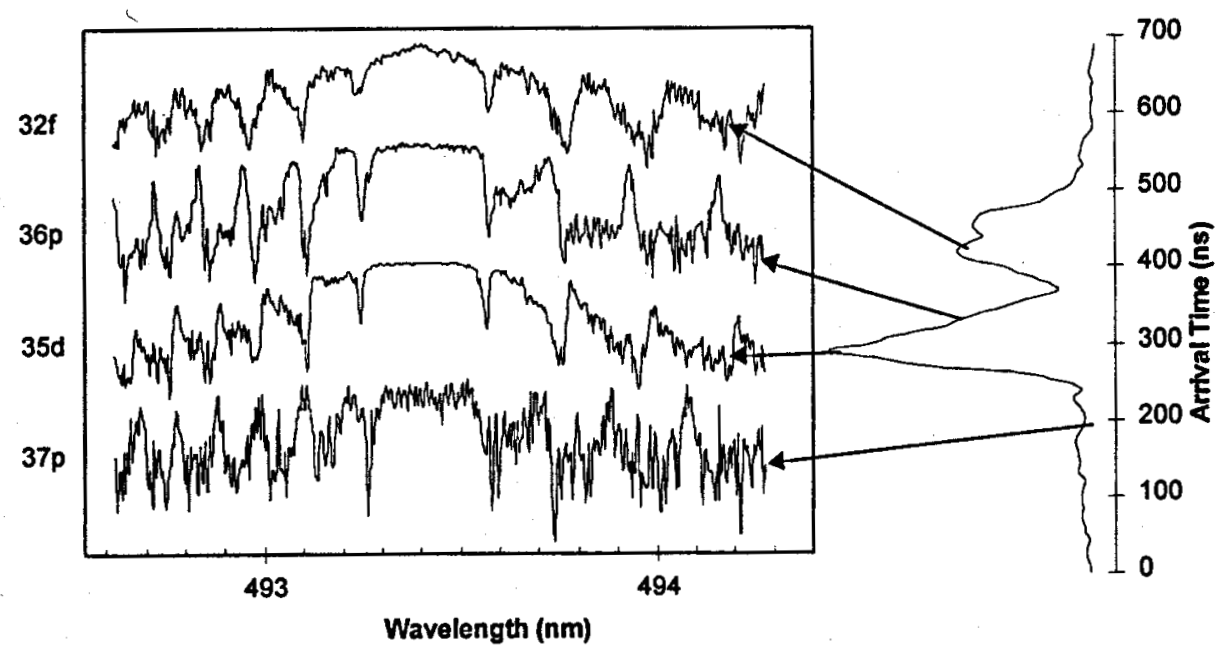

